\title{
Synthesis of Vanadium Interface for HFCVD Diamond Deposition on Steel Surface
}

\author{
Djoille Denner Damm ${ }^{a *}$, Andre Contin ${ }^{b}$,Vladimir Jesus Trava-Airoldib, Getúlio de Vasconcelos ${ }^{c}$, \\ Danilo Maciel Barquete ${ }^{d}$, Evaldo J. Corat ${ }^{b}$ \\ ${ }^{a}$ Universidade Federal de São Paulo, São José dos Campos, São Paulo, Brazil \\ bInstituto Nacional de Pesquisas Espaciais, São José dos Campos, São Paulo, Brazil \\ 'Instituto de Estudos Avançados, São José dos Campos, São Paulo, Brazil \\ ${ }^{d}$ Universidade Estadual de Santa Cruz, Ilhéus, Bahia, Brazil
}

Received: December 12, 2016; Accepted: June 11, 2017

\begin{abstract}
Laser cladding of vanadium carbide powder developed an interlayer on AISI D6 steel as a diffusional barrier and to relief thermal residual stress. Laser cladding experiments varied resolution (DPI) and scanning speed $(\mathrm{mm} / \mathrm{s})$. CVD diamond deposition on this interface went on by HFCVD technique. The coatings were characterized by X-ray diffraction analysis (XRD), scanning electron microscopy (SEM-FEG) and Raman spectroscopy. Ordered state $\mathrm{V}_{8} \mathrm{C}_{7}$ phase prevailed in the interlayer. The thickness of heat-affected zone (HAZ) and Laser Cladding Vanadium Coating (LCVC) were $37 \mu \mathrm{m}$ and $5 \mu \mathrm{m}$, respectively, in the best layer produced. The diamond film showed good quality and morphology. The Raman peak at $1342,13 \mathrm{~cm}^{-1}$ shows the residual stresses level undertaken at the film-substrate interface and the corresponding adhesion, demonstrating the suitability of the VC laser cladding process to CVD diamond films deposition.
\end{abstract}

Keywords: Vanadium Carbide, Hard Coatings, Laser Cladding, Thermal Stress, Diffusion Barrier and HFCVD Diamond

\section{Introduction}

The main problems to grow CVD diamond films directly on steel surface concern adhesion, crystallinity and purity. The difference between the thermal expansion coefficients of diamond and steel, about 11 times, results in residual compressive stress in the diamond film. Films usually delaminate during cooling from deposition temperature. Transition metals, as iron, on steel surface, catalyze graphitic $\mathrm{sp}^{2}$ bonds instead of diamond $\mathrm{sp}^{3}$ bonds and reduces film quality ${ }^{1}$. High carbon diffusion into steel is also an issue. An intermediate layer is necessary to create a transition zone to relieve the residual thermal stress and to act as a diffusion barrier both for transition metals and for carbon.

Coatings deposited on steel surface by laser cladding (LC) have some advantages to other conventional intermediate layers for CVD diamond deposition on steel substrates. These advantages are lower porosity; lower oxide contents; high integrity of fusion bonding between the surface layer and the substrate; and improved microstructure ${ }^{2}$. Its implementation allows faster and more efficient processing, easier automation and precise parameters control ${ }^{3}$. There are different ways to sinter using the laser cladding. The powders can be injected coaxially into the laser focal zone by a coaxial powder feeding. Easier to carry out is the two steps method. First spraying a powder dispersion over the substrate surface with a compressed air gun. In second step, the laser scans, always focused at the powder surface. In both cases powder and substrate melt to form molten pools, which solidify into fully dense metal layer after the laser focal spot moves away ${ }^{4}$. A CAD motion control program controls the motion of the laser focal spot to cover the entire surface.

Vanadium carbide (VC), like other early transition metal carbides, is a typical hard refractory ceramic. Widely employed in industrial applications, VC coating improves the life of metal forming tools because of its excellent properties at high temperatures: hardness, wear resistance, chemical resistance and thermal stability ${ }^{5}$. Vanadium carbide has chemical compatibility with carbon steel and CVD diamond ${ }^{6}$ and, has an intermediate thermal expansion coefficient between these materials ${ }^{7}$.

This work presents the use of two-step laser cladding with vanadium carbide powder. It forms an interlayer with vanadium compounds that enables excellent CVD diamond deposition on steel substrates. Laser cladding shows up as innovative and promising to develop intermediate layers for CVD diamond growth. It results in rapid processing, formation of The phases $\mathrm{V}_{8} \mathrm{C}_{7}, \mathrm{VCrFe}_{8}, \mathrm{Fe}_{2} \mathrm{O}_{3}$ and $\mathrm{Cr}_{2} \mathrm{Fe}_{14} \mathrm{C}$ within an extensive heat affected zone (HAZ) on steel surface.

\section{Materials and Methods}

\subsection{Laser cladding and HFCVD diamond process}

Commercially available (99\% pure) VC powder bought from Chengdu Best New Materials was the interface precursor. 
The average particle size was $10 \mu \mathrm{m}$. The substrate were disks (18 $\mathrm{mm}$ diameter X $4 \mathrm{~mm}$ height) cut from AISI D6 steel round bars, sanded with 220,400 and 600 grit sandpapers and cleaned in an acetone ultrasonic bath.

The laser cladding followed two steps. In the first step, the $\mathrm{VC}$ powders dispersed in isopropyl alcohol were sprayed on the samples surface using a spray gun. It dried at $100^{\circ} \mathrm{C}$ for $5 \mathrm{~min}$ before laser processing. In second step, the beam focused laser scanned powder surface. A weld pool forms on the substrate surface because of the beam energy absorption. Heat conduction promotes pool expansion and the substrate acts as an efficient heat sink causing rapid solidification of the coating. Systematic sintering parameters variation led to better adhesion and greater thickness of the VC interlayer. The laser beam sintering parameters were: resolution 300 , 600 and $900 \mathrm{dpi}$; scanning speed 100,300 and $500 \mathrm{~mm} / \mathrm{s}$ and only one NHC (number of heating cycles). The laser was a Synrad-SH with output power of $125 \mathrm{~W}$ and beam diameter of $200 \mu \mathrm{m}$. Beam intensity was $400 \mathrm{~kW} / \mathrm{cm}^{2}$ and nitrogen flow provided environment purging to avoid oxidation.

For the diamond film deposition, the following diamond growth conditions were adopted: pressure of 20 Torr, substrate temperature of $700{ }^{\circ} \mathrm{C}$, working distance from filament to substrate of $5 \mathrm{~mm}$, processing time of $3 \mathrm{~h}, 6 \mathrm{sccm}$ methane $\left(\mathrm{CH}_{4}\right)$ flow and $194 \mathrm{sccm}$ hydrogen $\left(\mathrm{H}_{2}\right)$ flow.

The characterization technique to analyze morphology and thickness of laser cladding intermediate coatings and HFCVD diamond film was field emission scanning electron microscopy (FEG-SEM, MIRA3 - TESCAN). Energy Dispersive X-ray Spectroscopy (EDS, X-MAX - Oxford) determined composition and distribution of the elements. X-ray diffractometry (Panalytical X'pert Pro) with radiation wavelength of $1,5418740 \AA(\mathrm{Cu}-\mathrm{K} \alpha)$ identified the phases and crystallographic orientation of intermediate coatings and the HFCVD diamond film. The diamond film residual thermal stress and purity were verified by Raman spectroscopy with laser excitation at $325 \mathrm{~nm}$ (HORIBA).

\section{Results and Discussion}

Figure 1 shows the substrate and VC powder characterization. Figure 1a shows the substrate and the VC powder phases by $\mathrm{X}$-ray diffraction. This information is important to evaluate phase changes after laser cladding. The AISI D6 tool steel difractogram shows the following phases: iron chromium $\left(\mathrm{CrFe}_{4}\right)$, iron carbide $\left(\mathrm{Fe}_{3} \mathrm{C}\right)$ and molybdenum (Mo). The VC powder has the following phases: vanadium carbide $\left(\mathrm{V}_{4} \mathrm{C}_{3}\right)$, vanadium oxide $\left(\mathrm{V}_{2} \mathrm{O}_{3}\right)$, iron manganese $\left(\mathrm{Fe}_{19} \mathrm{Mn}\right)$ and carbon $(\mathrm{C})$. The $\mathrm{VC}$ powder morphology presents particle size around 2-12 $\mu \mathrm{m}$, as shown in the Figure 2. The shape of the $\mathrm{VC}$ powder, without well-defined corners and with relative small particle size $(8 \mu \mathrm{m})$, needs less $\mathrm{CO}_{2}$ laser energy to melt and dissociate than coarser powders morphology8

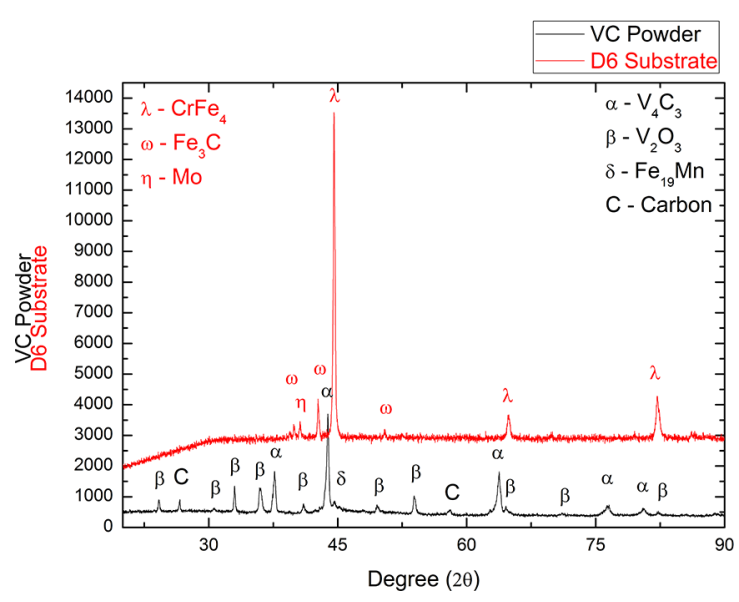

Figure 1. The materials characterization: The VC powder and substrate phase.

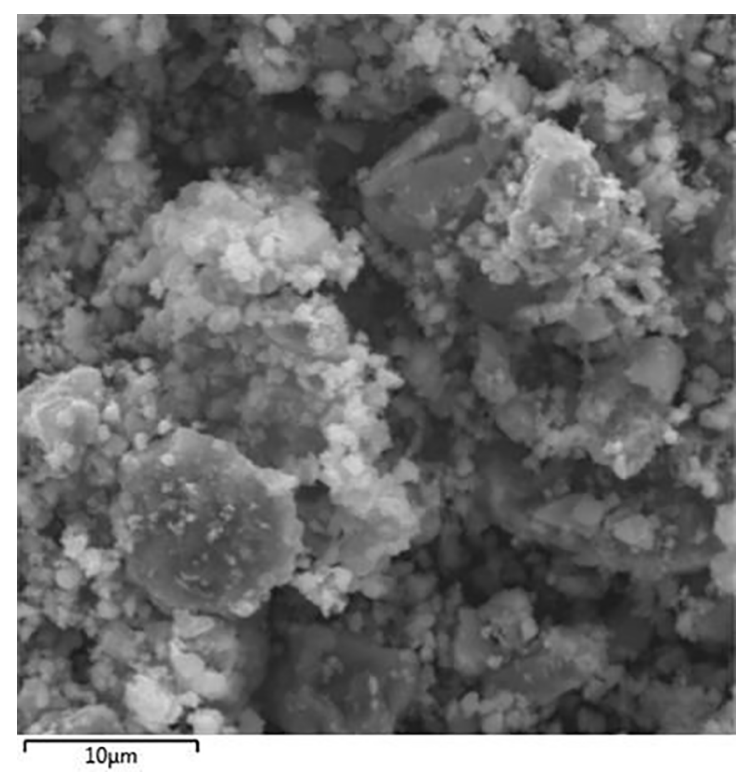

Figure 2. The materials characterization: The VC powder morphology.

During Laser Cladding Vanadium Coating (LCVC), we varied the laser parameters, as scan speed $(\mathrm{mm} / \mathrm{s})$ and resolution (DPI), to evaluate the morphology and composition of the compounds formed on the substrates surface. The best result showed up at $600 \mathrm{DPI}$ and $100 \mathrm{~mm} / \mathrm{s}$ and one heating cycle. Some samples presented extensive cracking in the coating. Others shows no vanadium carbide. Figure 3 shows the X-ray diffractogram of the laser cladding coating with characteristic peaks of $\mathrm{V}_{8} \mathrm{C}_{7}, \mathrm{VCrFe}_{8}, \mathrm{Fe}_{2} \mathrm{O}_{3}$ and $\mathrm{Cr}_{2} \mathrm{Fe}_{14} \mathrm{C}$ phases. The coatings mainly formed the ordered state $\mathrm{V}_{8} \mathrm{C}_{7}$ phase and had a preferential orientation of (222) and (400) planes. The $\mathrm{V}_{4} \mathrm{C}_{3}$ precursor powder recombined to form more complex vanadium carbides. The absorbed laser energy was enough to melt the powder and the steel surface to form new phases as seen in the X-ray difractogram (Figure 3). Figure 4 shows the morphology of the laser cladding coating. 


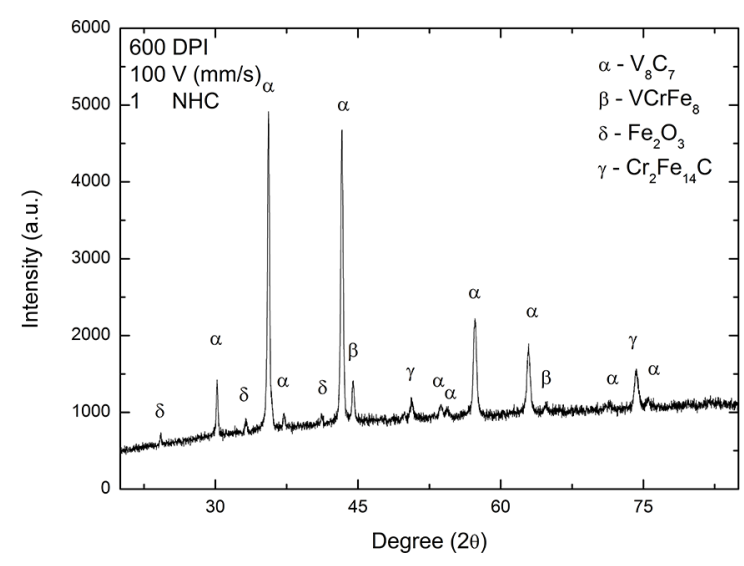

Figure 3. XRD diffractogram of the laser cladding vanadium coating (LCVC).

Figure 5 shows a cross-section of the AISI D6 coated by LCVC. The vanadium atoms diffuses into the substrate bulk up to $30 \mu \mathrm{m}$, as seen in the $\mathrm{V}$ depth concentration profile (Figure $5 \mathrm{~d}$ ). The heat absorbed by the powder layer transfers to substrate by conduction. This heat transfer, if efficient, forms molten pools on substrate surface ${ }^{9}$. The EDS mapping analysis performed in the cross section of the laser cladding coated sample (Figure 5b) shows the chromium distribution from surface to inner substrate in an extended heat affected zone (HAZ). The HAZ area is determined from depth concentration profile (Figure $5 \mathrm{~d}$ ) as the region located between the interface LCVC and the substrate. The HAZ depth can be correlated to laser beam speed and resolution. Original matrix chromium aggregates dissociated and homogeneously spread along the HAZ and the LCVC coating (Figure 5b). Figure 5d shows a uniform chromium distribution in the HAZ. The substrate bulk is the region where the $\mathrm{Cr}$ atoms concentration increases to level of the original $\mathrm{Cr}$ concentration in the substrate. The chromium

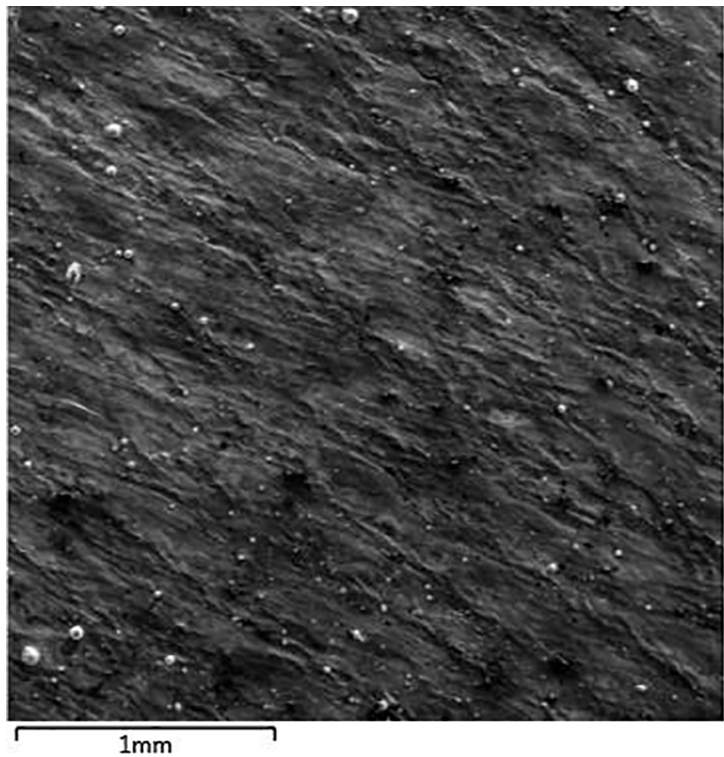

Figure 4. SEM-FEG images of the laser cladding vanadium coating (LCVC).

concentration increases in the LCVC coating. This high chromium diffusibility and its spreading through coating and substrate contributes to increase the LCVC coating adherence to substrate and to strengthen the LCVC coating. During the molten pool formation, chromium reacts both with matrix $\left(\mathrm{Cr}_{2} \mathrm{Fe}_{14} \mathrm{C}\right)$ and $\mathrm{VC}$ powder $\left(\mathrm{VCrFe}_{8}\right)$ forming an excellent, extensive and porous free metallurgical bonding. Chromium increases steel resistance against wear and oxidation at high temperatures ${ }^{10}$, fills the empty spaces and flaws ${ }^{11}$, and reduces porosity on the surface ${ }^{12}$. The strong bond between the coating and substrate should stand for the high compressive stresses induced on LCVC layer in the cooling stage from HFCVD processing. Steel thermal expansion coefficient is higher than coating layer one.

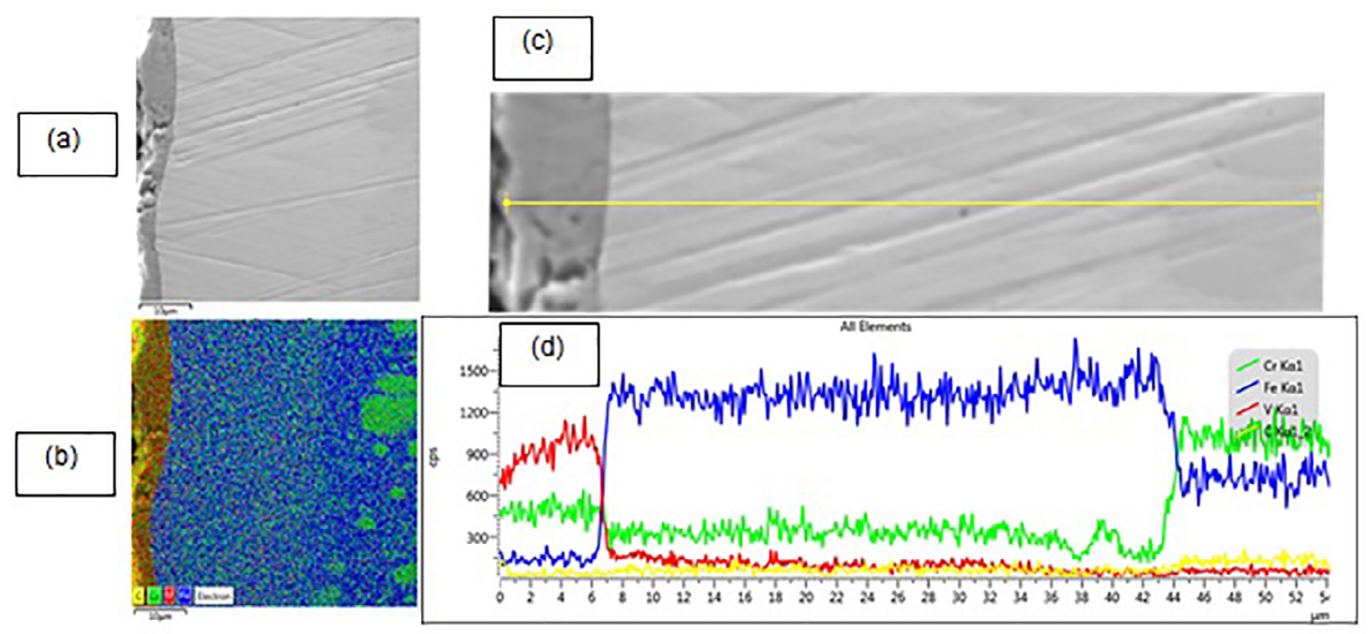

Figure 5. The laser cladding vanadium coating characterization: a) Cross-section Image; b) Mapping; c) Line scan image and depth concentration profile. 
The depth concentration profile (Figure 5d) presents a decrease in the Fe atoms concentration at a depth of 6 $\mu \mathrm{m}$ from coating surface. Fe atoms migrated from bulk to LCVC coating because of the molten pool expansion. Line scan analysis shows around $5 \mu \mathrm{m}$ LCVC coating thickness.

We evaluated nine scanning parameters sets for the laser beam to get different HAZ. The maximum HAZ depth, around $64 \mu \mathrm{m}$ (Figure 6), arises from combining high resolution (900 DPI) and lower scanning speed $(100 \mathrm{~mm} / \mathrm{s})$, resulting in more energy transferred to the molten pool. An increase in the interaction time between laser beam and $\mathrm{VC}$ powder increases the energy conducted to the substrate and enlarges the HAZ, as shown in the Figure 6.

Figure 7 shows FEG-SEM image of the diamond film deposited on the sample coated with laser cladding, using the parameters 600 DPI and $100 \mathrm{~mm} / \mathrm{s}$. Diamond film showed well-defined grains, with less than $1 \mu \mathrm{m}$ size with low surface roughness. These characteristics are adequate to cutting tool with high performance and prolonged life. All samples had diamond coating fragmented into tiny pieces. For the sample coated with laser parameters of 600 DPI and $100 \mathrm{~mm} / \mathrm{s}$, diamond film had a Raman shift at 1342, $13 \mathrm{~cm}^{-1}$ in the regions where the diamond film remained adherent. The high thermal stresses induced by the substrate during reactor cooling down can explain the diamond film crack. This tiny cracking on LCVC coating is distinct from diamond films directly deposited on steel substrates, in which diamond grows over a loose graphitic interlayer and the film fragments into large pieces during ramp down cooling ${ }^{13}$. The energy and the laser cladding local time for sample with 600 DPI and $100 \mathrm{~mm} / \mathrm{s}$ has been enough to form intermediate layers with high surface roughness. Probably, it increases the diamond film adhesion by mechanical interlocking ${ }^{14}$. In early stage HFCVD growth, diamond nuclei probably grow

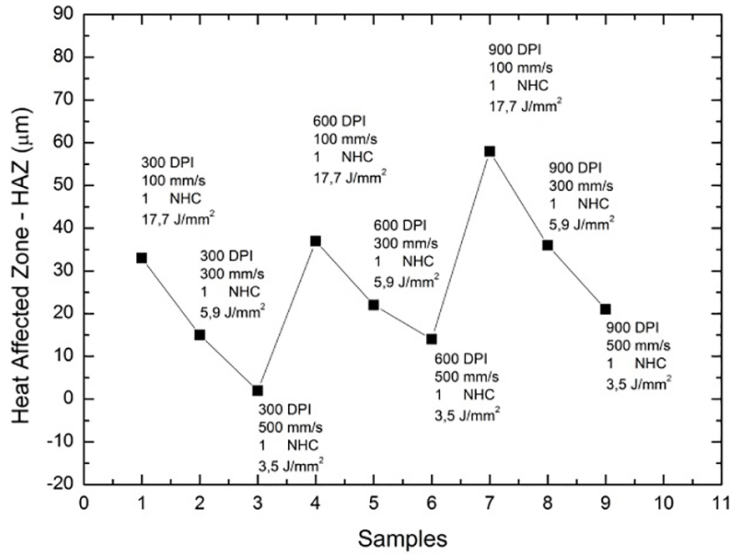

Figure 6. Depth of heat affected zone dependence to laser beam scanning parameters.

inside the surface cavities left by laser cladding on LCVC coating surface. This may produce the interlocking action.

The Raman peak shift shows if the stress state of the film is under tension or compression ${ }^{15,16}$. The reference peak was the natural non-stressed diamond peak position $\left(v_{\mathrm{o}}\right)$, at 1332 $\mathrm{cm}^{-1}{ }^{17,18}$. Values found above the reference peak means the film is in a compressive state ${ }^{19}$. Results equal or less than $1332 \mathrm{~cm}^{-1}$ may mean total or partial delamination of the CVD diamond film. The stress state of diamond films on LCVC surface was calculated by the expression ${ }^{20,21}: \sigma=-0.567$ $\left(v_{\mathrm{m}}-v_{\mathrm{o}}\right)$; Equation (1).

Figure 8a shows the typical Raman spectrum. The Raman peak at $1342,13 \mathrm{~cm}^{-1}\left(v_{\mathrm{m}}\right)$ is a characteristic of carbon $\mathrm{sp}^{3}$ hybridized, shifted about $10,13 \mathrm{~cm}^{-1}$ from $v_{0}$. Equation (1) gives diamond compressive stress of 5,74 GPa. This stress state without delamination proves the LCVC coating capacity in absorbing and spreading the tensions from substrate along the transition zone. However, the Raman

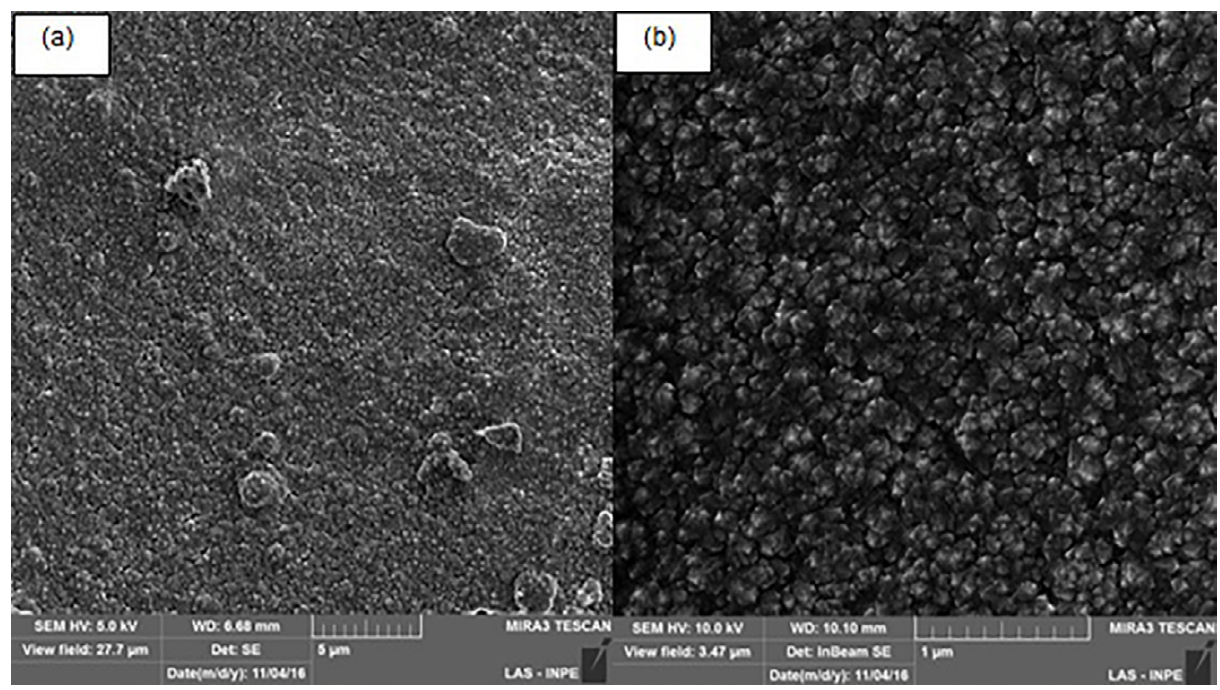

Figure 7. The HFCVD Diamond Image: a) diamond morphology at lower magnification and b) diamond well-defined corners at higher magnification. 
spectrum showed that CVD film needs improvement on quality and crystallinity. The presence of a Raman peak at $1586,45 \mathrm{~cm}^{-1}$ suggests a notable graphitic formation in the diamond film. To reduce the residual stress in the diamond film we increasing the graphitization level in the diamond film using $3 \%$ of methane in the gas mixture. The X-ray difractogram (Figure $8 \mathrm{~b}$ ) shows the crystalline diamond peak in the LCVC coating.
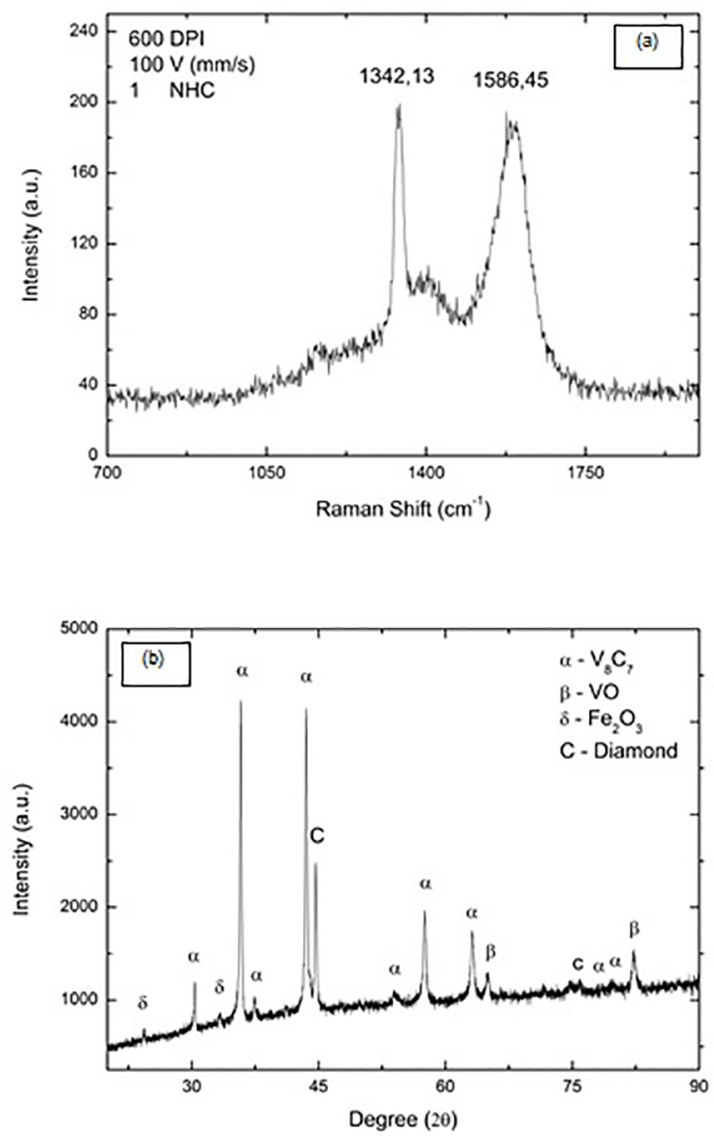

Figure 8. The HFCVD diamond peak: a) Raman spectrum and b) $\mathrm{X}$-ray diffractogram.

\section{Conclusions}

We performed laser cladding of VC powders on AISI D6 steel samples by varying resolution $(300,600$ and 900) DPI and scanning speed $(100,300$ and 500$) \mathrm{mm} / \mathrm{s}$. We studied the crystalline phases, element distribution, morphology, LCVC sintering, HFCVD growth, crystallinity and diamond stress state. Based on these results, the following conclusions are clear:

I. Laser cladding was effective in creating a coating on AISI D6 steel surface. The phases $\mathrm{V}_{8} \mathrm{C}_{7}, \mathrm{VCrFe}_{8}$, $\mathrm{Fe}_{2} \mathrm{O}_{3}$ and $\mathrm{Cr}_{2} \mathrm{Fe}_{14} \mathrm{C}$ formed in the this LCVC coating;
II. Chromium diffuses through HAZ and LCVC coating to form $\mathrm{Cr}_{2} \mathrm{Fe}_{14} \mathrm{C}$ and $\mathrm{VCrFe}_{8}$ phases. This provides a high strength metallurgical bond and improves adhesion between matrix and LCVC;

III. The HAZ extended to a depth of $64 \mu \mathrm{m}$ for LC beam parameters of 900 DPI and $100 \mathrm{~mm} / \mathrm{s}$. 600 DPI and $100 \mathrm{~mm} / \mathrm{s}$ were the best parameters for diamond deposition. The energy and interaction time between VC powder and substrate was enough to provide $5 \mu \mathrm{m}$ thick LCVC coating and $37 \mu \mathrm{m}$ of HAZ. The transition zone was effective to relief and withstand compressive stresses of 5,74 GPa in the diamond film.

IV. The HFCVD diamond shows a good adhesion to the LCVC coating surface but we still have to improve crystallinity and purity. Multilayers of LCVC powder laser cladding will be tested to upgrade the barrier against iron migration and avoid graphite formation and ensure high HFCVD diamond quality.

\section{Acknowledgments}

The authors wish to acknowledge support from FAPESP (20015/25149-2) and FAPESB/CAPES (edital 017/2015). We also acknowledge Federal University of São Paulo (UNIFESP), the National Institute for Space Research (INPE) and Associated Laboratory of Sensors and Materials (LAS) for supporting this scientific research.

\section{References}

1. May PW, Harvey JN, Allan NL, Richley JC, Mankelevich YA. Simulations of chemical vapor deposition diamond film growth using a kinetic Monte Carlo model. Journal of Applied Physics. 2010;108(1):014905.

2. Herrera Y, Grigorescu IC, Ramirez J, Di Rauso C, Staia MH. Microstructural characterization of vanadium carbide laser clad coatings. Surface and Coatings Technology. 1998;108109:308-311.

3. Shah SV, Dahotre NB. Laser surface-engineered vanadium carbide coating for extended die life. Journal of Materials Processing Technology. 2002;124(1-2):105-112.

4. Qin R, Zhang X, Guo S, Sun B, Tang S, Li W. Laser cladding of high Co-Ni secondary hardening steel on 18Cr2Ni4WA steel. Surface \& Coatings Technology. 2016;285:242-248.

5. Teghil R, De Bonis A, Galasso A, Villani P, Santagata A, Ferro $\mathrm{D}$, et al. Nanostructured thin films obtained by ultra-short pulse laser deposition of vanadium carbide. Applied Surface Science. 2009;255(10):5220-5223.

6. Barquete DM, Corat EJ, Campos RA, Moura Neto C, TravaAiroldi VJ. Thermodiffused vanadium carbide interface for diamond films on steel and cemented carbides substrates. Surface Engineering. 2010;26(7):506-510. 
7. Krajewiski A, D’Alessio L, De Maria G. Physico-Chemical and Thermophysical Properties of Cubic Binary Carbides. Crystal Research \& Technology. 1998;33(3):341-374.

8. Luikov AV, Shashkov AG, Vasiliev LL, Fraiman YE. Thermal conductivity of porous systems. International Journal of Heat and Mass Transfer. 1968;11(2):117-140.

9. Contin A, Vasconcelos G, Barquete DM, Campos RA, TravaAiroldi VJ, Corat EJ. Laser cladding of SiC multilayers for diamond deposition on steel substrates. Diamond and Related Materials. 2016;65:105-114.

10. Mougin J, Dupeux M, Antoni L, Galerie A. Adhesion of thermal oxide scales grown on ferritic stainless steels measured using the inverted blister test. Materials Science and Engineering $A$. 2003;359(1-2):44-51.

11. Sabioni ACS, Huntz AM, Philibert J, Lesage B, Monty C. Relation between the oxidation growth rate of chromia scales and self-diffusion in $\mathrm{Cr}_{2} \mathrm{O}_{3}$. Journal of Materials Science. 1992;27(17):4782-4790.

12. Galerie A, Toscan F, Dupeux M, Mougin J, Lucazeau G, Valot C, et al. Stress and adhesion of chromia-rich scales on ferritic stainless steels in relation with spallation. Materials Research. 2004;7(1):81-88.

13. Li YS, Tang Y, Yang Q, Xiao C, Hirose A. Growth and adhesion failure of diamond thin films deposited on stainless steel with ultra-thin dual metal interlayers. Applied Surface Science. 2010;256(24):7653-7657.

14. Chandran M, Kumaran CR, Vijayan S, Bhattacharya SS, Rao MSR. Adhesive Microcrystalline Diamond Coating on Surface
Modified Non-Carbide Forming Substrate Using Hot Filament CVD. Materials Express. 2012;2(2):115-120.

15. Correia RRB, Alcantara Jr. P, Cunha SL. Dye-induced spectral narrowing of stimulated scattering in $\mathrm{CS}_{2}$. Chemical Physics Letters. 1999;313(3-4):553-558.

16. Bachmann PK, Wiechert DU. Characterization and Properties of Artificially Grown Diamond In: Clausing RE, Horton LL, Angus JC, Koidl P, eds. Diamond and Diamond Like Film and Coatings. New York: Plenum Press; 1991. p. 677-714.

17. Knight DS, White WB. Characterization of diamond films by Raman spectroscopy. Journal of Materials Research. 1989;4(2):385-392.

18. Ferrari AC, Robertson J. Resonant Raman spectroscopy of disordered, amorphous, and diamond like carbon. Physical Review B. 2001;64(7):075414.

19. Ferrari AC, Robertson J. Origin of the $1150-\mathrm{cm}^{-1}$ Raman mode in nanocrystalline diamond. Physical Review $B$. 2001;63(12):121405(R).

20. Ager JW, Drory MD. Quantitative measurement of residual biaxial stress by Raman spectroscopy in diamond grown on a Ti alloy by chemical vapor deposition. Physical Review $B$. 1993;48(4):2601.

21. Ali N, Cabral G, Sein H, Ahmed W, Neto VF, Gracio J. Polycrystalline Diamond Films Deposited onto Flat Cemented WC-Co Substrates and WC-Co Dental Burs of Similar Chemical Composition. In: Euro PM 2002 Hard Materials Proceedings; 2002 Oct 7-9; Lausanne, Switzerland. p. 154-159. 